OPEN ACCESS

Edited by:

Pankaj Kumar Arora,

Babasaheb Bhimrao Ambedkar

University, India

Reviewed by:

Willem J. H. Van Berkel,

Wageningen University \& Research,

Netherlands

Shaohua Chen,

South China Agricultural University,

China

M. Oves,

King Abdulaziz University,

Saudi Arabia

*Correspondence:

Hongzhi Tang

tanghongzhi@sjtu.edu.cn

Changzheng Cui

cuichangzheng@ecust.edu.cn

Specialty section:

This article was submitted to Microbiotechnology, Ecotoxicology

and Bioremediation,

a section of the journal

Frontiers in Microbiology

Received: 28 November 2017

Accepted: 31 May 2018

Published: 06 July 2018

Citation:

Chen X, Tang H, Liu Y, Xu P, Xue Y, Lin K and Cui $C$ (2018) Purification and Initial Characterization of 3-Hydroxybenzoate 6-Hydroxylase

From a Halophilic Martelella Strain AD-3. Front. Microbiol. 9:1335. doi: 10.3389/fmicb.2018.01335

\section{Purification and Initial Characterization of 3-Hydroxybenzoate 6-Hydroxylase From a Halophilic Martelella Strain AD-3}

\author{
Xin Chen ${ }^{1}$, Hongzhi Tang ${ }^{2 *}$, Yongdi Liu' ${ }^{1}$, Ping $X u^{2}$, Yong Xue ${ }^{3}$, Kuangfei Lin ${ }^{1}$ and \\ Changzheng Cui ${ }^{1 *}$
}

${ }^{1}$ State Environmental Protection Key Laboratory of Environmental Risk Assessment and Control on Chemical Process, School of Resources and Environmental Engineering, East China University of Science and Technology, Shanghai, China, ${ }^{2}$ State Key Laboratory of Microbial Metabolism and School of Life Sciences and Biotechnology, Shanghai Jiao Tong University, Shanghai, China, ${ }^{3}$ Eco-environmental Protection Research Institute, Shanghai Academy of Agricultural Sciences, Shanghai, China

3-Hydroxybenzoate 6-hydroxylase, an NADH-dependent flavoprotein, can convert 3hydroxybenzoate which is an important intermediate in the biodegradation of many aromatic hydrocarbons. 3-Hydroxybenzoate is metabolized by entering the TCA cycle through the gentisate pathway. We found a putative $3 \mathrm{HB} 6 \mathrm{H}$ gene from a cluster that potentially encodes for gentisic acid degradation from a halophilic Martelella sp. strain AD-3. The corresponding protein was expressed with an $\mathrm{N}$-terminal His-tag and purified by $\mathrm{Ni}^{2+}$-nitrilotriacetic acid affinity chromatography. The protein showed an overexpressed band of about $46 \mathrm{kDa}$ by SDS-PAGE, and it was also proven that the enzyme contains FAD by absorption spectroscopy and HPLC analysis. The optimal activity of $3 \mathrm{HB} 6 \mathrm{H}$ from strain $\mathrm{AD}-3$ was observed in phosphate buffer $(\mathrm{pH} \mathrm{8.0)}$ at $37^{\circ} \mathrm{C}$ without salinity $(\mathrm{NaCl})$ and metal salts. The $K_{m}$ values of 3-hydroxybenzoate $6-$ hydroxylase were determined to be $72.6 \pm 10.1 \mu \mathrm{M}$ and $104.1 \pm 18.2 \mu \mathrm{M}$ for $400 \mu \mathrm{M}$ $\mathrm{NADH}$ and 3-hydroxybenzoate, respectively. Site-directed mutagenesis showed that residues 305, 306 and 308 are important for FAD binding. In addition, we found that Tyr221 and Gln305 of 3HB6H from strain AD-3 are involved in substrate binding.

Keywords: moderate halophilic bacteria, 3-hydroxybenzoate, 3-hydroxybenzoate 6-hydroxylase, purification, FAD binding

\section{INTRODUCTION}

3-Hydroxybenzoate (3HB) is a compound commonly found in the environment, it is an intermediate of lignin biodegradation (Ko et al., 2009) and is used as a corrosion inhibitor (Narváez et al., 2005). It also appears in the gentisate pathway for the degradation of 2,5-xylenol, 3,5-xylenol and $m$-cresol (Hopper and Chapman, 1971; Hopper et al., 1971). There are two pathways for the aerobic degradation of 3HB, the gentisate (2,5-dihydroxybenzoate) pathway and the protocatechuate (3,4-dihydroxybenzoate) pathway through the catalysis of 3-hydroxybenzoate 
6-hydroxylase $(3 \mathrm{HB} 6 \mathrm{H})$ and 3-hydroxybenzoate 4-hydroxylase $(3 \mathrm{HB} 4 \mathrm{H})$, respectively (Yano and Arima, 1958). $3 \mathrm{HB} 6 \mathrm{H}$ is an $\mathrm{NADH}$-dependent flavoprotein that contains FAD as a redoxactive cofactor, and its quaternary structure is dimer (Montersino et al., 2013). This enzyme catalyzes the para-hydroxylation of 3-hydroxybenzoate to yield gentisate, in which consists of a reductive and oxidative half-reaction (Sucharitakul et al., 2013). In the catalytic reaction of $3 \mathrm{HB} 6 \mathrm{H}, 3 \mathrm{HB}$ is preferred to bind as the first substrate, followed by NADH that leaves prior to the reaction with oxygen (Sucharitakul et al., 2013). Several 3HB6H have been purified and characterized, including $3 \mathrm{HB} 6 \mathrm{H}$ from Pseudomonas cepacia (Wang et al., 1987), Ncgl2923 from Corynebacterium glutamicum ATCC 13032 (Yang et al., 2010), NagX from Polaromonas naphthalenivorans CJ2 (Park et al., 2007), 3HB6H from Rhodococcus jostii RHA1 (Montersino and van Berkel, 2012), and XlnD from Pseudomonas alcaligenes NCIMB 9867 (Gao et al., 2005). Among them, the crystal structure of $3 \mathrm{HB} 6 \mathrm{H}$ from Rhodococcus jostii RHA1 has been reported that contains one molecule of FAD, one chloride-ion, and a phospholipid ligand (phosphatidylglycerol and phosphatidylethanolamine) in each subunit (Montersino et al., 2013). Recently, the new phospholipid ligand (phosphatidylinositol) was found in $\mathrm{Rj} 3 \mathrm{HB} 6 \mathrm{H}$ when the enzyme was homologously expressed in Rhodococcus jostii RHA1\#2 (Montersino et al., 2017). In addition, site-directed replacements were able to affect the enzyme activity by affecting substrate binding, substrate hydroxylation or other properties (Liu et al., 2005; Montersino et al., 2013; Sucharitakul et al., 2015).

Halophilic Martelella sp. AD-3, isolated from highly saline petroleum-contaminated soil, was highly effective in degrading many PAHs with low-ring numbers, such as phenanthrene and anthracene, under broad salinities $(0.1-15 \%)$ and varying $\mathrm{pH}$ values (6.0-10.0) (Feng et al., 2012; Cui et al., 2014). We found a gene (02545) encoding a putative 3HB6H (AZF01_02545) from the genomic sequence of halophilic Martelella sp. AD-3 (Cui et al., 2016). In strain AD-3, the gene is located upstream of $g d o$, whose expression and functions have been characterized previously (Huang et al., 2015). The $3 \mathrm{HB} 6 \mathrm{H}$ from strain AD-3 has $57 \%$ identity with XlnD from Pseudomonas alcaligenes NCIMB 9867 as determined by BlastP search.

In this study, we report the expression of the gene (02545) encoding a putative $3 \mathrm{HB} 6 \mathrm{H}$ in Escherichia coli. The corresponding enzyme was purified and characterized. In addition, we changed residues 221, 305, 306 and 308 by sitedirected mutagenesis to study their possible involvement in substrate and FAD binding.

\section{MATERIALS AND METHODS}

\section{Chemicals and Media}

3-Hydroxybenzoate (98\% purity), salicylate (99\% purity), 4hydroxybenzoate ( $99 \%$ purity), gentisate ( $98 \%$ purity) and FAD (95\% purity) were purchased from Aladdin (Shanghai, China), and NADH was purchased from Sangon Biotech (Shanghai, China). All other reagents and solvents used were analytical grade and the highest purity available. Luria-Bertani (LB) medium
(10 g/L tryptone, $5 \mathrm{~g} / \mathrm{L}$ yeast extract, and $10 \mathrm{~g} / \mathrm{L} \mathrm{NaCl}$ ) was used for both culturing and cloning. Solid agar plates were prepared with the addition of $1.5 \%(\mathrm{w} / \mathrm{v})$ agar to the LB liquid medium.

\section{Bacterial Strains, Plasmids, and Growth Conditions}

Escherichia coli DH5 $\alpha$ was used as the host for cloning experiments, while E. coli BL21(DE3) was used as the host for expressing the gene (02545). All the E. coli strains were grown in $\mathrm{LB}$ medium containing $50 \mathrm{mg} / \mathrm{L}$ kanamycin on a rotary incubator (200 rpm) at $37^{\circ} \mathrm{C}$.

\section{DNA and Amino Acid Sequence Data Analysis}

The amino acid sequences of the 3-hydroxybenzoate 6hydroxylases, 3-hydroxybenzoate 4-hydroxylases and salicylate 1-hydroxylases from other strains were obtained from GenBank. All the homology searches were carried out on the NCBI BLAST server ${ }^{1}$ with nucleotide BLAST and protein BLAST. These obtained sequences were compared with the sequence from strain $\mathrm{AD}-3$. Conserved binding domain searches were performed using Vector NTI DNA analytical software (version 11.0). Phylogenetic analysis was performed using MEGA 7. Protein structures were predicted by I-TASSER (Roy et al., 2010).

\section{Cloning and Overexpression of the Putative 3HB6H Gene}

The gene (02545) was amplified from the genomic DNA of strain AD-3 using pfu DNA polymerase (Vazyme, China). The primers, which are the EcoRI (underlined) and HindIII (underlined) recognition sites, respectively, were designed as follows: 02545forward (5'-CCGGAATTCATGTCAAACGTCGCAAATGA-3') and 02545-reverse (5'-CCCAAGCTTTCAGGCCGAGACCGCG CCTT-3'). The amplified PCR product obtained was then excised with EcoRI and HindIII and ligated into pET28a(+), resulting in the recombinant plasmid designated pET28a-02545. The plasmid pET28a-02545 was subsequently transformed in E. coli BL21(DE3) to produce the protein with the His-tag located at $N$-terminal. E. coli BL21(DE3) carrying pET28a-02545 was cultured in $\mathrm{LB}$ medium containing $50 \mathrm{mg} / \mathrm{L}$ kanamycin and shaken at $37^{\circ} \mathrm{C}$ to an $\mathrm{OD}_{600}$ of $0.6-0.8$. Then, after adding isopropyl $\beta$-D-thiogalactoside (IPTG) to a final concentration of $0.2 \mathrm{mM}$, the cultures were incubated for $16 \mathrm{~h}$ at $16^{\circ} \mathrm{C}$ or $30^{\circ} \mathrm{C}$ to express the protein. The cells were harvested by centrifugation at $9,000 \times g$ for $20 \mathrm{~min}$ at $4^{\circ} \mathrm{C}$ and resuspended in binding buffer ( $25 \mathrm{mM}$ Tris- $\mathrm{HCl}, 300 \mathrm{mM} \mathrm{NaCl}$, and $20 \mathrm{mM}$ imidazole, $\mathrm{pH}$ 8.0). The cells were sonicated 40 times for $3 \mathrm{~s}$ at $6 \mathrm{~s}$ intervals with an ultrasonic disintegrator in an ice bath and then centrifuged at $10,000 \times \mathrm{g}$ for $20 \mathrm{~min}$ at $4^{\circ} \mathrm{C}$ to separate the soluble protein from the insoluble membrane and protein aggregates. The supernatant was used for SDS-PAGE analysis. SDS-PAGE was performed using $12.5 \%$ acrylamide for the separating gel and $3.25 \%$ acrylamide for the stacking gel.

\footnotetext{
${ }^{1}$ http://www.ncbi.nlm.nih.gov/BLAST
} 


\section{Conversion of 3-Hydroxybenzoate by Using Resting Cells}

Small-scale resting cell assays were performed as described previously (Panke et al., 1998) using an $\mathrm{OD}_{600}$ of 5.0 in $50 \mathrm{mM}$ phosphate buffer ( $\mathrm{pH}$ 8.0) containing $200 \mu \mathrm{M} 3$ hydroxybenzoate at $200 \mathrm{rpm}$ and $30^{\circ} \mathrm{C}$. During the course of the conversion, the concentrations of 3-hydroxybenzoate and gentisate were monitored by High Performance Liquid Chromatography (HPLC) and Liquid Chromatograph-Mass Spectrometer (LC-MS) systems (Agilent 1200 series, Agilent 1290 series ultra performance liquid chromatograph and TOFMS 6230, Agilent Technologies Inc., United States). For HPLC analysis, the sample of direct sampling was centrifuged at $10,000 \times g$ for $2 \mathrm{~min}$. And then the supernatant was filtered through a $0.22 \mu \mathrm{m}$ millipore filter to prepare the samples. $10 \mu \mathrm{L}$ of each sample was injected onto an Eclipse XDBC18 column $(4.6 \times 150 \mathrm{~mm}$; particle size, $5 \mu \mathrm{m})$ and run at $30^{\circ} \mathrm{C}$ with $50 \%$ methanol and $50 \%$ water (containing $1 \% 0$ formic acid) as the eluent at a flow rate of $0.8 \mathrm{~mL} / \mathrm{min}$. The concentrations of 3-hydroxybenzoate and gentisate were detected by UV spectroscopy at $235 \mathrm{~nm}$ and $320 \mathrm{~nm}$. For LC-MS analysis, the conditions of liquid chromatography were the same as those of HPLC, and the mass spectrum adopted a negative ion mode.

\section{Purification of Putative 3HB6H From Strain AD-3}

The cell cultures were induced for $16 \mathrm{~h}$ at $30^{\circ} \mathrm{C}$ and then disrupted by ultrasonic wave. After centrifugation, the supernatant was filtered through a $0.22 \mu \mathrm{m}$ filter, and the resultant filtrate was applied to a $5 \mathrm{~mL}$ column of Ni-NTA agarose (GE, Healthcare, Little Chalfont, United Kingdom) that had been equilibrated with the binding buffer. After a wash with $30 \mathrm{~mL}$ of washing buffer $(25 \mathrm{mM}$ Tris- $\mathrm{HCl}, 300 \mathrm{mM} \mathrm{NaCl}$, and 70 mM imidazole, $\mathrm{pH}$ 8.0), His $_{6}$-tagged 3HB6H from strain AD-3 was eluted from the column using elution buffer $(25 \mathrm{mM}$ Tris$\mathrm{HCl}, 300 \mathrm{mM} \mathrm{NaCl}$, and $200 \mathrm{mM}$ imidazole, $\mathrm{pH}$ 8.0). All the purification steps were carried out at $4^{\circ} \mathrm{C}$.

\section{Protein Determination and Enzyme Assays}

The concentration of the purified protein was measured by the Bradford method (Kruger, 1994). The Native-PAGE was performed using $7-15 \%$ gel. The protein was scanned using the full wavelength mode of a spectrophotometer after dilution with phosphate buffer ( $\mathrm{pH} 8.0)$, and the wavelengths detected were from 250 to $550 \mathrm{~nm}$. The identification of the protein binding to FAD was detected by HPLC. The protein was boiled for $3 \mathrm{~min}$ to isolate the cofactor, and the liquid chromatography conditions were the same as those used to determine the HspB cofactor (Tang et al., 2011). The concentration standard curve of FAD is shown in Supplementary Figure S4A. Lipid extraction was performed as described by van Berkel and coworkers (Montersino et al., 2013). Lipid identification was performed in solution containing $50 \%$ methanol and $50 \%$ acetonitrile (containing $2 \%$ formic acid), and was measured in a negative ion mode. $3 \mathrm{HB} 6 \mathrm{H}$ activity was measured following NADH oxidation activity as a decrease in the absorbance at $360 \mathrm{~nm}$ (Montersino and van Berkel, 2012). Activity was assayed in $1 \mathrm{~mL}$ of reaction mixture containing $400 \mu \mathrm{M}$ NADH, $400 \mu \mathrm{M}$ 3-hydroxybenzoate and $10 \mu \mathrm{g}$ enzyme extract in $50 \mathrm{mM}$ phosphate buffer $(\mathrm{pH} 8.0)$ at $30^{\circ} \mathrm{C}$ with a UV2550 spectrophotometer (Shimadzu, Kyoto, Japan). The molar absorption coefficient of NADH used to determine the reaction of 3-hydroxybenzoate was $\varepsilon_{360}=3.50 \mathrm{mM}^{-1} \cdot \mathrm{cm}^{-1}$ (Supplementary Figure S4B). Enzyme activity was assayed during $60 \mathrm{~s}$ after adding the enzyme to the reaction mixture. The hydroxylation efficiencies were determined by UV-2550 spectrophotometer and HPLC which detecting the change of NADH and $3 \mathrm{HB}$, respectively.

\section{Kinetics Studies}

A series of 3-hydroxybenzoate solutions ranging from 50 to $1000 \mu \mathrm{M}$ was prepared to determine the $K_{\mathrm{m}}$ values in $400 \mu \mathrm{M}$ NADH. The $K_{\mathrm{m}}$ values of $3 \mathrm{HB} 6 \mathrm{H}$ for $\mathrm{NADH}$ were measured in $400 \mu \mathrm{M}$ 3-hydroxybenzoate with concentrations of $\mathrm{NADH}$ ranging from 10 to $800 \mu \mathrm{M}$. Spectrophotometric assays (absorbance at $360 \mathrm{~nm}$ ) were completed while maintaining a constant enzyme concentration in $50 \mathrm{mM}$ potassium phosphate buffer $(\mathrm{pH} 8.0)$ at $30^{\circ} \mathrm{C}$. Kinetic parameters were determined from Lineweaver-Burk plots.

\section{Site-Directed Mutagenesis}

Site-directed mutagenesis was performed by using a recombinant PCR method. The primers are listed in Supplementary Table S1. The restriction sites were EcoRI (underline) and HindIII (underline). The recombinant pET28a that contained the mutant genes was transformed into E. coli BL21(DE3) followed by overexpression and purification. The strain growth, protein purification and enzyme assay methods are described above.

\section{RESULTS}

\section{Sequence Analysis of Putative 3HB6H From Strain AD-3}

Putative $3 \mathrm{HB} 6 \mathrm{H}$ from strain $\mathrm{AD}-3$ was found to belong to a family of group A flavoprotein monooxygenases that includes salicylate 1-hydroxylases, 3-hydroxybenzoate 4-hydroxylases and so on. (Montersino et al., 2011; Montersino and van Berkel, 2012; Huijbers et al., 2014). It was then compared with reported proteins and showed $34-57 \%$ identity with 3-hydroxybenzoate 6hydroxylases, $23-28 \%$ identity with salicylate 1-hydroxylases, and only $15-17 \%$ identity with 3 -hydroxybenzoate 4 -hydroxylases. In particular, putative $3 \mathrm{HB} 6 \mathrm{H}$ from strain $\mathrm{AD}-3$ revealed $57 \%$ identity compared with $\mathrm{X} \ln \mathrm{D}$ from Pseudomonas alcaligenes NCIMB 9867 (Gao et al., 2005) and only 34\% identity compared with Rj3HB6H from Rhodococcus jostii RHA1 (Montersino and van Berkel, 2012). A phylogenetic tree was constructed with 3-hydroxybenzoate 6-hydroxylases, salicylate 1hydroxylases and 3-hydroxybenzoate 4-hydroxylases from other 17 strains and confirmed that it is most closely related to 3HB6H from Pseudomonas alcaligenes NCIMB 9867 (Figure 1A). The complete sequence alignment is shown in Supplementary Figure S1. 

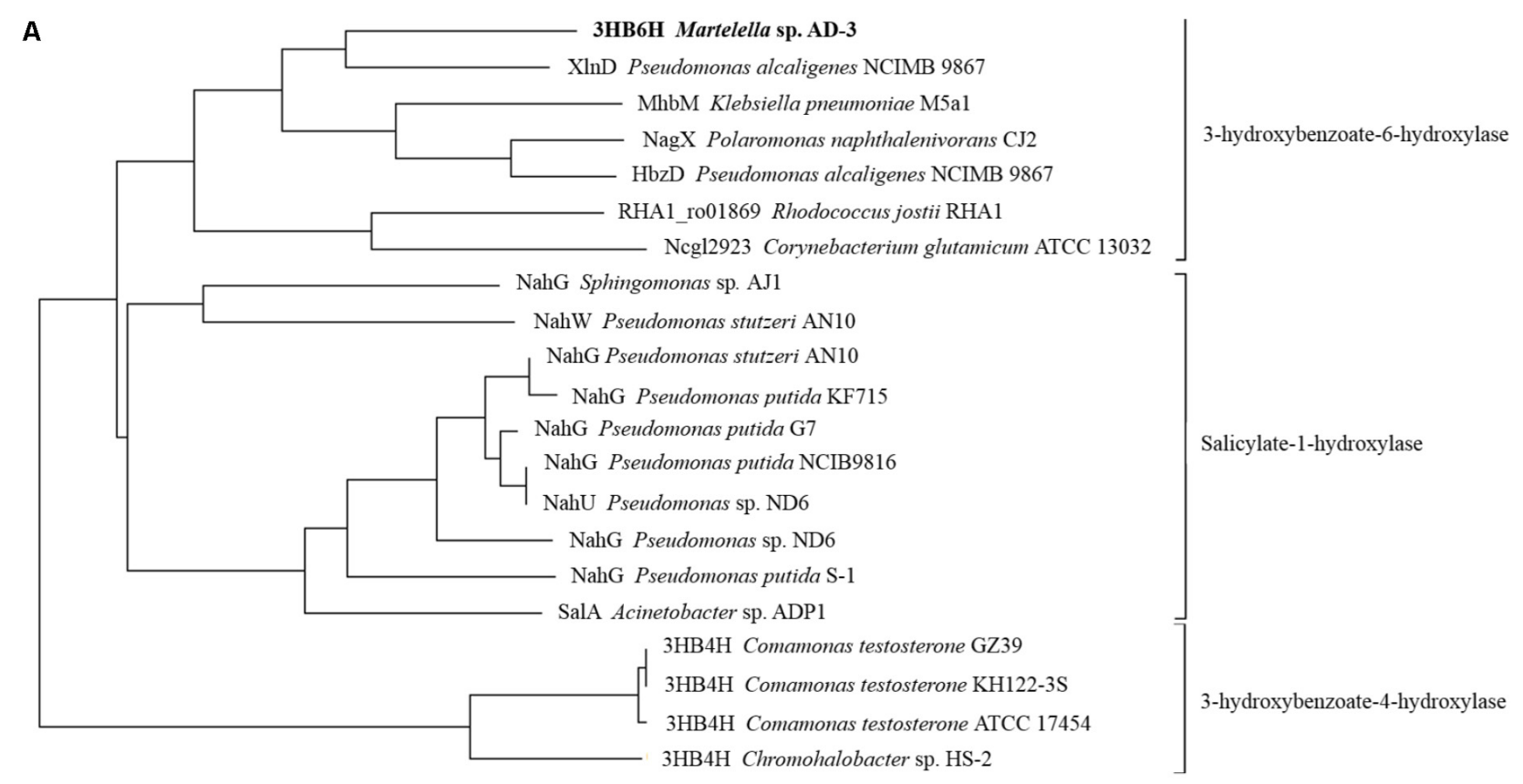

B

10

GxGxGG motif

(1) 1

10

20

30

48

AZF01_02545 AD-3

(1) - - MSNVANEADP I L I A GGG I G GAAAI GLANKGLKS LVLERAPKLGE

XInD NCIMB 9867

(1) - - - - - - MHNN I L I A GAG I G GLSAAL G LAR KGMRS I VLEKAPELGE

NagX CJ2

MhbM M5a1

RHA1_ro01869 RHA1

(1) - - - MS DN PADL PVLVAGGGIGG LAAALALVRRGF SVKVLEQAPEIGE

Ncgl2923 ATCC 13032

(1) - - - - - MAKVMRA I IVGGG I G GAATALS LARQ G I KVMLLEKAHE I GE

(1) - - - MSNLQDAR I I I GGG I GGAANALALAQKGANVTLFERASEFGE

Consensus

(1) MSLPHSDELRGQKIIISGGGIGGAAGALALALRGADVTLYERAAEFKE

(1)

R I I I GGG I GG LAA A A LARKG I KV I L LERAPE I GE

(145) $145 \quad 150 \quad 160 \quad 170$ DG motif, 180

192

AZF01_02545 AD-3 (136) EVVDYDQDENGVTA I L KD GERLKGT I L I GADGLW SNVRKKVVGDGAPR

XInD NCIMB 9867 (130) EVVDYENF P DRVEA I LHD G S C INGAVLVGAPGLWSNVRQ KV I GD GDPR

NagX CJ2 (135) RALRIEQDEGSVTVYDQHGNAHKG I ALIGA PGVKSVVREQFVGDA - AR

MhbM M5a1 (132) QVVDIRQTADDVTVFDDKGNSWTADI L I GCPGGKSVVRQSLLGDS - PR

RHA1_ro01869 RHA1 (133) TVTDVITEGDKA IVSTDDGRTHEAD I ALGMPGLKSRLREKISGDE - PV Ncgl2923 ATCC 13032 (145) VDG I EVD I ES S I K GEDNKTLLVDA F LA F P I H S VMR KKLVDDA - PV Consensus (145) VVDIEQD D VTV DDG TL GDILIGAPGLKSVVR KLVGDA PR

(289) 289

300

310GD motif

320

336

AZF01_02545 AD-3 (272) QDWKRWVLCDRDPVENWIDGRVVLLGDAAHPMMQYFAQGACMAMEDAV

XInD NCIMB 9867 (267) - NWKRWVLCDRD PLPNWVDGRVTLLGDAAH PMMQYMAQGASMAIEDAV NagX CJ2 (271) - TWKRWATADREP I GQWSFGRVTLLGDAAHPTTQYMAQGACMAMEDGV

MhbM M5a1 (268) - SWRRWSTADREPVEKWGNDRITLVGDAAHPVAQYMAQGACMALEDAV

RHA1_ro01869 RHA1 (269) - KDRWW PMYDRE P I ENWVDGRM I L L G DAA H P P LQY LA S GAVMA I E DAK

Ncgl2923 ATCC 13032 (287) - RNNWWQMSDREPLENWR I GRMLLLGDAAHAPLQY LASGAVMAMEDAE Consensus (289) WKRW LADREP IENWVDGRVTLLGDAAHPMLQYMAQGACMAMEDAV

FIGURE 1 | Amino acid sequence analysis results. (A) Neighbor-joining tree of 3-hydroxybenzoate 6-hydroxylase, salicylate hydroxylase and 3-hydroxybenzoate 4-hydroxylase. Aligned sequences are from halophilic Martelella sp. AD-3 (AMM83381.1), Pseudomonas alcaligenes NCIMB 9867 (Q9F131.1), Klebsiella pneumoniae M5a1 (AAW63416.1), Polaromonas naphthalenivorans CJ2 (Q3S4B7.1), Corynebacterium glutamicum ATCC 13032 (Q8NLB6.1), Rhodococcus jostii RHA1 (ABG93680.1), Sphingomonas sp. AJ1 (BAA19150.1), Pseudomonas stutzeri AN10 (AAD02157.1 and AAD02146.1), Pseudomonas putida KF715 (AAB35960.1), Pseudomonas putida G7 (AAA25897.1), Pseudomonas putida NCIB9816 (CAA58778.1), Pseudomonas sp. ND6 (AAP44222.1 and AAP44249.1), Pseudomonas putida S-1 (BAA61829.1), Acinetobacter sp. ADP1 (AAF04312.1), Comamonas testosteroni GZ39 (AAR25885.1), Chromohalobacter sp. HS-2 (AFK24467.1), Comamonas testosteroni ATCC 17454 (ABN58516.1), and Comamonas testosteroni KH122-3S (BAF34928.1). (B) Excerpts of sequences used for multiple sequence alignment performed by the Vector NTI program. Aligned sequences are from above. 


\section{Overexpression and Functional Verification of Putative 3HB6H From Strain AD-3 in BL21(DE3)}

The gene (02545) was cloned into the expression vector pET28a. E. coli BL21(DE3) containing the plasmid pET28-02545 was induced for $16 \mathrm{~h}$ in $\mathrm{LB}$ medium supplemented with $0.2 \mathrm{mM}$ IPTG at $16^{\circ} \mathrm{C}$ and $30^{\circ} \mathrm{C}$, respectively. The SDS-PAGE revealed an overexpressed band of about $46 \mathrm{kDa}$ and showed the amount of soluble protein which induced at $30^{\circ} \mathrm{C}$ was more than that which induced at $16^{\circ} \mathrm{C}$ in same conditions (Figure 2A). To determine the protein encoded by the gene (02545) is a 3 hydroxybenzoate 6-hydroxylase, we used resting cell reaction to detect the conversion of hydroxybenzoate at $30^{\circ} \mathrm{C}$ by HPLC. The Figures $\mathbf{2 B}, \mathbf{C}$ clearly showed that the concentration of 3 hydroxybenzoate decreased and the concentration of gentisate increased. The mass spectrometry data of LC-MS confirmed that the substracte was 3-hydroxybenzoate and the product was gentisate (Figure 2D). Thus, the protein encoded by the gene (02545) is a 3-hydroxybenzoate 6-hydroxylase.

\section{Purification and Characterization of 3HB6H From Strain AD-3}

Protein $3 \mathrm{HB} 6 \mathrm{H}$ was purified by using Ni-NTA, and the yellow protein was obtained. SDS-PAGE showed an overexpressed band of about $46 \mathrm{kDa}$, which is $3 \mathrm{HB} 6 \mathrm{H}$ (Figure 3A). And the Native-PAGE showed a band of $90 \mathrm{kDa}$. Therefore, the $3 \mathrm{HB} 6 \mathrm{H}$ from strain AD-3 might be dimeric protein (Supplementary Figure S2). The UV-VIS absorption spectrum showed maximum absorbance at 274,375 , and $452 \mathrm{~nm}$, with a minimum at $410 \mathrm{~nm}$ and a shoulder at $480 \mathrm{~nm}$ (Figure 3B). The A274/A452 ratio of the FAD-saturated protein preparation was 11.5. The FAD concentration in the purified $3 \mathrm{HB} 6 \mathrm{H}(0.29 \mathrm{mM})$ was $0.30 \mathrm{mM}$, and FAD/enzyme ratio was $1.02 \pm 0.05$ by HPLC analysis. The result of identifying protein-bound lipids showed that the $3 \mathrm{HB} 6 \mathrm{H}$ expressed in E. coil contained phosphatidylglycerol, while phosphatidylethanolamine was not detected (Supplementary Figure S3 and Supplementary Table S2). In addition to its detection in vivo, the reaction resulting in the conversion of 3-hydroxybenzoate to gentisate was detected by ultraviolet

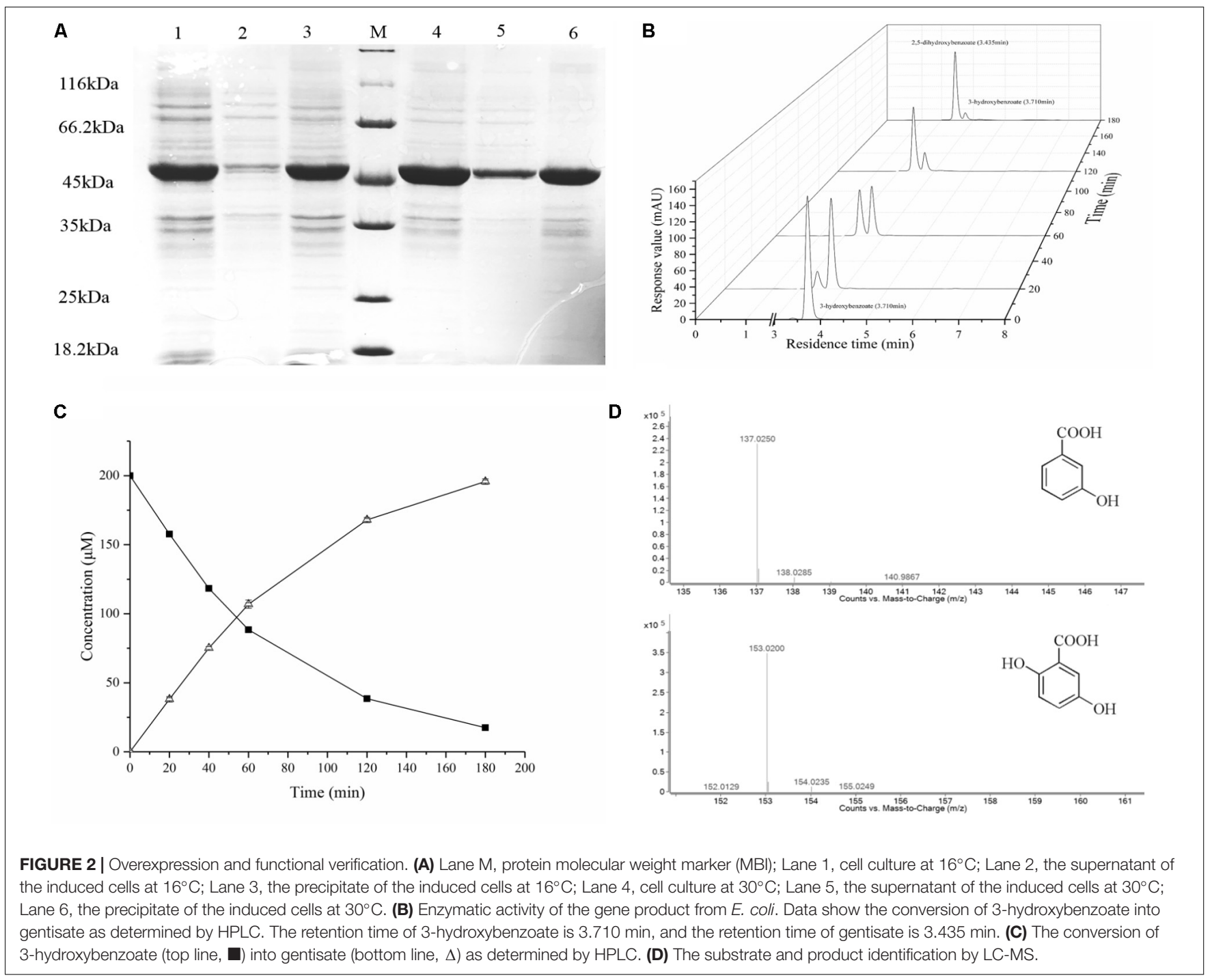



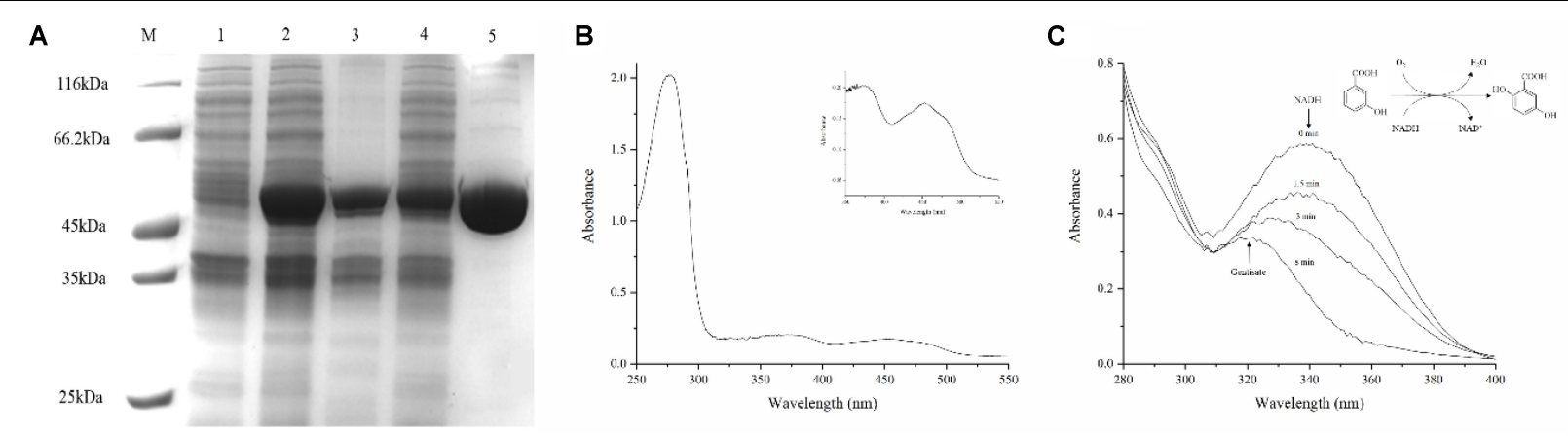

FIGURE 3 | Purification of 3HB6H from strain AD-3. (A) Lane M, protein molecular weight marker (MBI); Lane 1, cell culture of cells transfected with the empty vector (pET28a) at $30^{\circ} \mathrm{C}$; Lane 2, cell culture at $30^{\circ} \mathrm{C}$; Lane 3 , the precipitate of the induced cells at $30^{\circ} \mathrm{C}$; Lane 4 , the supernatant of the induced cells at $30^{\circ} \mathrm{C}$; Lane 5 , the purified $3 \mathrm{HB} 6 \mathrm{H}$ protein. (B) The full-wavelength scanning results of $3 \mathrm{HB} 6 \mathrm{H}$. (C) The full-wavelength scanning in vitro conversion of 3-hydroxybenzoate by $3 \mathrm{HB} 6 \mathrm{H}$.

spectrophotometry in vitro. The peak of NADH at $340 \mathrm{~nm}$ was reduced and moved to $320 \mathrm{~nm}$ (the peak of gentisate) over the course of time in reaction mixture containing $200 \mu \mathrm{M} \mathrm{NADH}$ and $200 \mu \mathrm{M}$ 3-hydroxybenzoate (Figure 3C). The activity was measured $60 \mathrm{~s}$ after the addition of $3 \mathrm{HB}$ to reactions with different $\mathrm{pH}$ buffers. Citric acid-sodium citrate, phosphate, Tris- $\mathrm{HCl}$, and sodium carbonate-sodium bicarbonate buffers were used for incubation at $\mathrm{pH} 4.0-6.0,6.0-8.0,8.0-9.0$, and 9.0-11.0 with identical concentration $(50 \mathrm{mM})$, respectively. $3 \mathrm{HB} 6 \mathrm{H}$ showed maximal stability in phosphate buffer ( $\mathrm{pH} 8.0$ ). However, Tris$\mathrm{HCl}$ ( $\mathrm{pH}$ 8.0) obviously inhibited the activity of AZF01_02545 (Figure 4A). The effect of metal salts at $0.5 \mathrm{mM}\left(\mathrm{Ca}^{2+}, \mathrm{Mg}^{2+}\right.$, $\mathrm{Fe}^{3+}, \mathrm{Cu}^{2+}, \mathrm{Zn}^{2+}, \mathrm{Ba}^{2+}, \mathrm{Co}^{2+}$, and $\left.\mathrm{Mn}^{2+}\right)$ was examined. $\mathrm{Ca}^{2+}$ and $\mathrm{Mn}^{2+}$ had no effect on enzyme activity. $\mathrm{Mg}^{2+}, \mathrm{Fe}^{3+}, \mathrm{Cu}^{2+}$, $\mathrm{Zn}^{2+}$, and $\mathrm{Co}^{2+}$ reduced enzyme activity. The addition of $\mathrm{Cu}^{2+}$ reduced enzyme activity to $16.8 \%$, and even the addition of $\mathrm{Zn}^{2+}$ reduced enzyme activity to $22.6 \%$ (Figure $4 \mathrm{~B}$ ). To assess temperature stability, $3 \mathrm{HB} 6 \mathrm{H}$ was incubated in phosphate buffer ( $50 \mathrm{mM}, \mathrm{pH} 8.0$ ) for $60 \mathrm{~min}$ at temperatures ranging from 16 to $50^{\circ} \mathrm{C}$ for assay activity. The enzyme activity was maintained at $16-37^{\circ} \mathrm{C}$, and quickly lost at higher temperatures. The enzyme precipitated initially at $42^{\circ} \mathrm{C}$ and precipitated completely at $50^{\circ} \mathrm{C}$ (Figure $4 \mathrm{C}$ ). The influence of reaction temperature on enzyme activity was also investigated at the temperature range from 16 to $50^{\circ} \mathrm{C}$ in phosphate buffer ( $\mathrm{pH} 8.0$ ). The maximal enzyme activity was observed at $37^{\circ} \mathrm{C}$, and the specific activity was $25.2 \mathrm{U} / \mathrm{mg}$ (Figure 4D). The effect of salinity on $3 \mathrm{HB} 6 \mathrm{H}$ activity was measured in phosphate buffer $(\mathrm{pH} 8.0)$ at $30^{\circ} \mathrm{C}$, with salinity ranging from 0 to $85.56 \mathrm{mM}$. With the increase in salinity, enzyme activity clearly decreased. The activity reached to $3 \%$ in $85.56 \mathrm{mM}$ salinity (Figure $4 \mathrm{E}$ ). Therefore, the maximum activity is $25.2 \mathrm{U} / \mathrm{mg}$ in optimal conditions which is phosphate buffer $(\mathrm{pH} 8.0)$ at $37^{\circ} \mathrm{C}$ without salinity $(\mathrm{NaCl})$ and metal salts.

\section{Kinetic Properties}

The purified $3 \mathrm{HB} 6 \mathrm{H}$ displayed typical Michaelis-Menten kinetics, and Lineweaver-Burk plots of enzyme activity yielded an apparent $K_{\mathrm{m}}$ of $72.6 \pm 10.1 \mu \mathrm{M}$ and $k_{\text {cat }}$ of $5.7 \pm 0.2 \mathrm{~s}^{-1}$ for 3-hydroxybenzoate when the concentration of $\mathrm{NADH}$ was fixed at $400 \mu \mathrm{M}$ and the concentrations of 3-hydroxybenzoate were varied (Figure 5A). At a constant level of 3-hydroxybenzoate $(0.4 \mathrm{mM})$ and various amounts of $\mathrm{NADH}$, the protein exhibited an apparent $K_{\mathrm{m}}$ of $104.1 \pm 18.2 \mu \mathrm{M}$ and $k_{\text {cat }}$ of $7.8 \pm 0.4 \mathrm{~s}^{-1}$ for NADH (Figure 5B).

\section{Site-Directed Mutations}

Multiple sequence alignments with five enzymes known to be 3hydroxybenzoate 6-hydroxylases (Montersino et al., 2017) with the Vector NTI program revealed three conserved motifs in the protein encoded by gene (02545), namely, the GxGxGG moiety, GD moiety and DG moiety (Figure 1B). The GxGxGG moiety (Gly15 Gly17 Gly19 Gly20 in 3HB6H from strain AD-3) is a conserved motif at the $N$-terminal region of $\mathrm{NAD}(\mathrm{P}) \mathrm{H}$ dependent and FAD-containing oxidoreductases. This moiety is important for binding the ADP moiety of FAD (Wierenga et al., 1986). The GD motif (Gly297 Asp298 in 3HB6H from strain AD3 ) is the second FAD-binding motif in flavoproteins and contacts the O3' of the ribose moiety of FAD (Eggink et al., 1990). The DG motif (Asp166 Gly167 in 3HB6H from strain AD-3) serves a dual role in the recognition of FAD and NADH and is highly conserved among all flavoprotein hydroxylases studied (Eppink et al., 1997). Some sites in the GD region associated with FAD binding were obtained by I-TASSER.

We then obtained four mutants: Q305P, Y306H, A308G, and $X$ (site mutations of 305,306 , and 308). In addition, we substituted a site (Tyr221) that was different from most salicylate hydroxylases in the same site (Phe) and obtained Y221F. The mutants were then purified; the enzyme activity and the amount of FAD binding of these mutant proteins compared to the wildtype protein are shown in Table 1 . The enzyme activity of the mutant proteins was lower than the wild-type protein.

\section{DISCUSSION}

$3 \mathrm{HB} 6 \mathrm{H}$ plays an important role in the gentisate pathway of degradation $3 \mathrm{HB}$ in many bacteria. Previous reports were all found in non-halophilic organisms. This is the first report of a $3 \mathrm{HB} 6 \mathrm{H}$ found in a halophilic Martelella strain. 
A

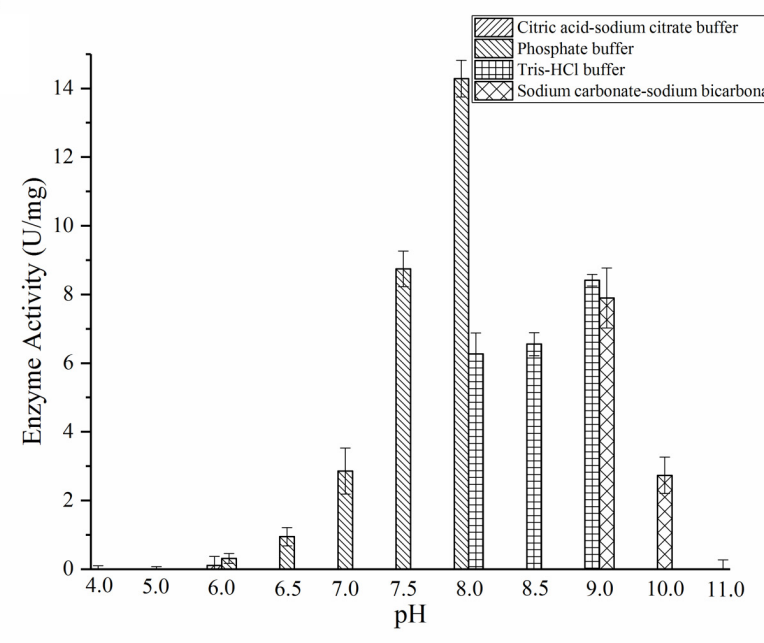

C

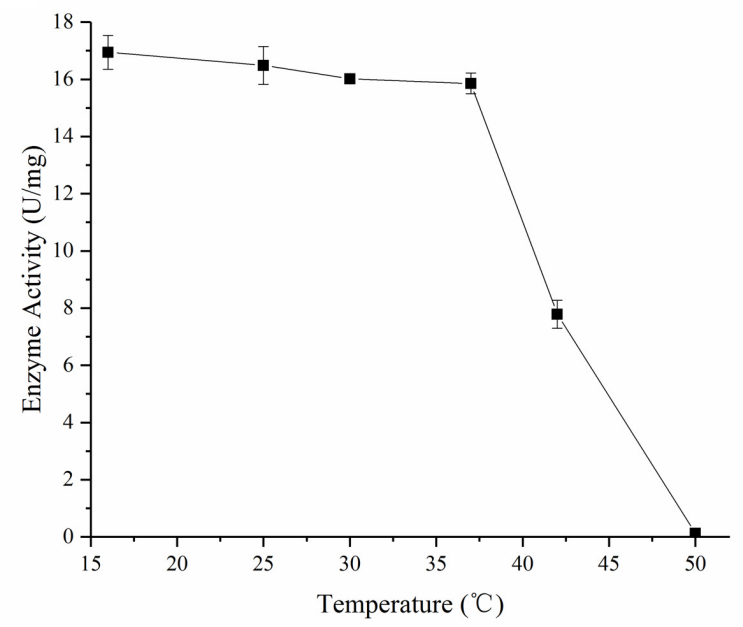

E

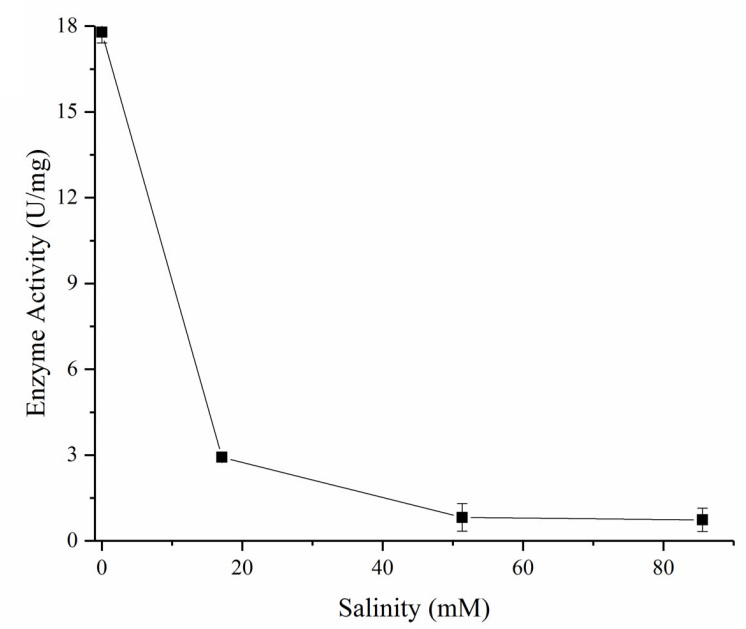

B

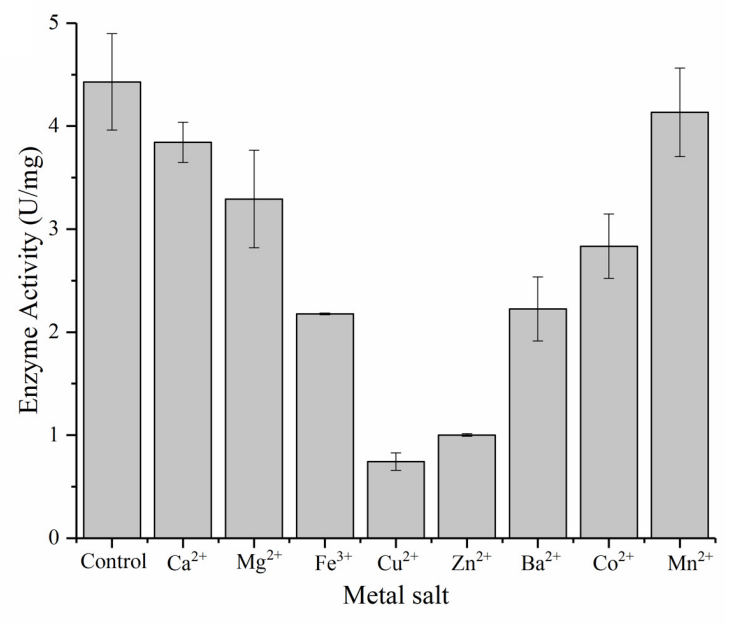

D

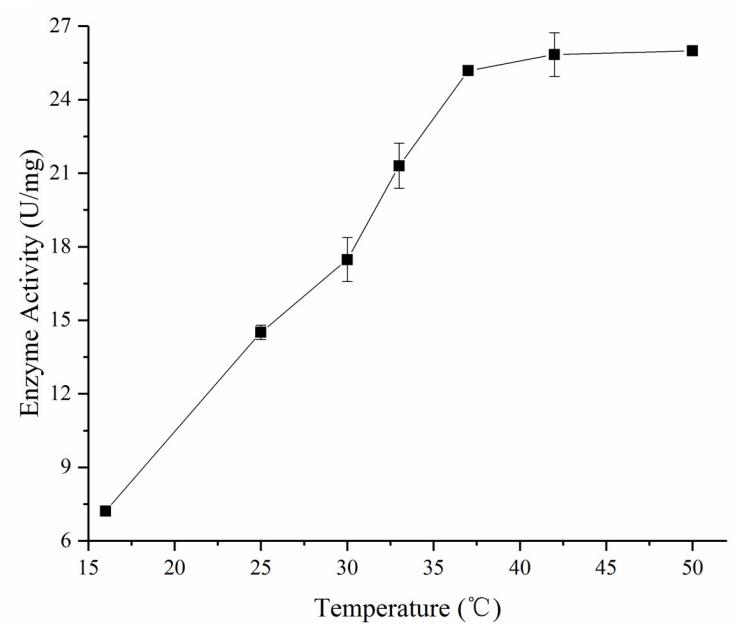

FIGURE 4 | Characterization of 3HB6H from strain AD-3. (A) pH optimization of 3HB6H. 3HB6H has optimal activity in phosphate buffer (pH 8.0). (B) Effects of metal salts on enzyme activity; control without metal salt. $\mathrm{Ca}^{2+}, \mathrm{Mg}^{2+}, \mathrm{Fe}^{2+}, \mathrm{Cu}^{2+}, \mathrm{Zn}^{2+}, \mathrm{Ba}^{2+}, \mathrm{Co}^{2+}$ and $\mathrm{Mn}^{2+}$. (C) Temperature stability of $3 \mathrm{HB} 6 \mathrm{H}$ activity. The enzyme activity was maintained at $16^{\circ} \mathrm{C}$ to $37^{\circ} \mathrm{C}$. (D) Temperature sensitivity of $3 \mathrm{HB} 6 \mathrm{H}$ activity; optimal activity was obtained at $37-50^{\circ} \mathrm{C}$. (E) Salinity dependence of $3 \mathrm{HB} 6 \mathrm{H}$ activity; maximum enzyme activity was observed without salt. 

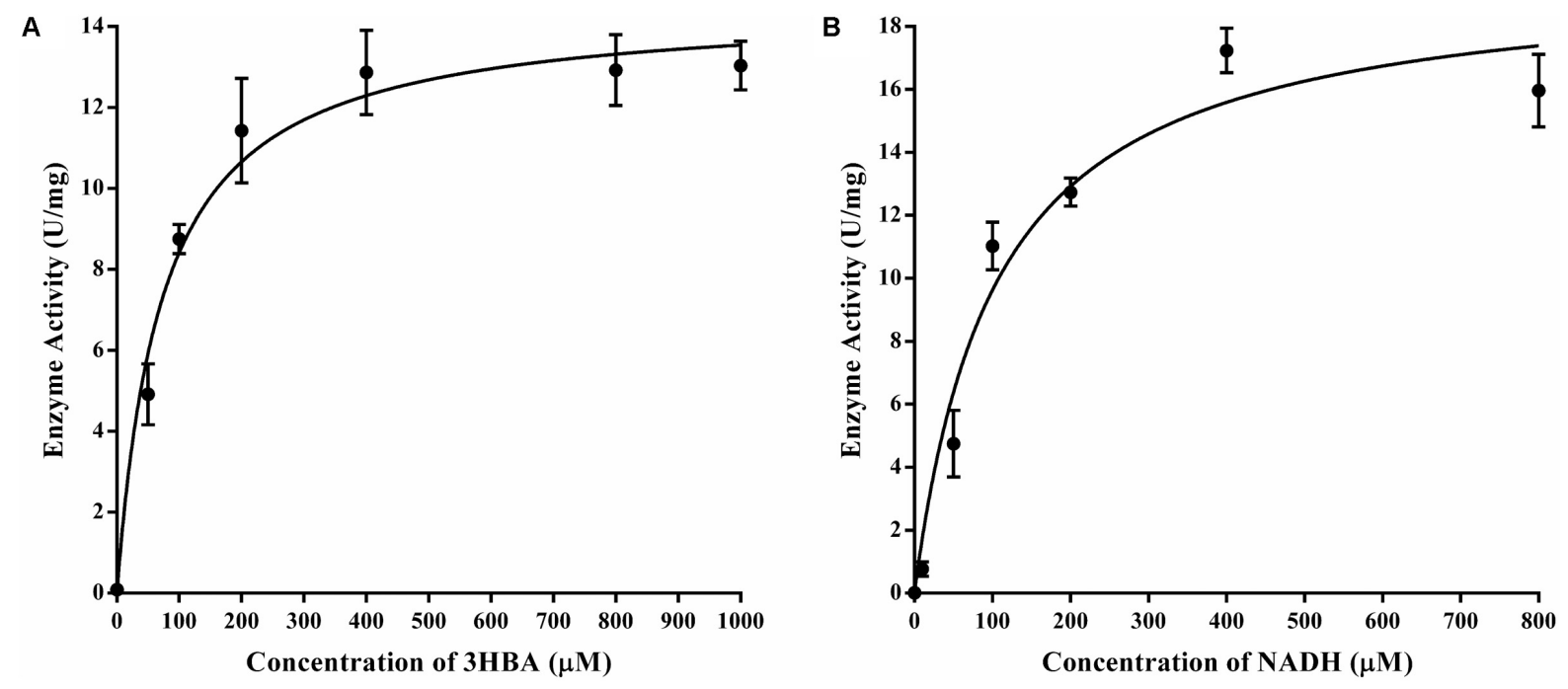

FIGURE 5 | Enzyme kinetics of 3HB6H from strain AD-3. (A) A mixture containing $400 \mathrm{mM}$ NADH in 50 mM phosphate buffer (pH 8.0) was mixed with an equal volume of enzyme (17.18 mg/ml). The $K_{\mathrm{m}}$ values for 3-hydroxybenzoate $\mathbf{( B )}$ at a constant level of 3-hydroxybenzoate (0.4 mM) and various amounts of NADH; the $K_{\mathrm{m}}$ values for $\mathrm{NADH}$.

\section{The Characteristics of 3HB6H From Strain AD-3}

Amino acid sequence analysis revealed that $3 \mathrm{HB} 6 \mathrm{H}$ from strain AD-3 has moieties similar to those of most 3-hydroxybenzoate 6-hydroxylases and salicylate hydroxylases; these moieties are the GxGxGG moiety, GD moiety and DG moiety (Figure 1B). Full-wavelength scanning showed a typical characteristic of flavoproteins (Figure 3B). The A274/A452 ratio of the FADsaturated protein preparation was 11.5 , and each $3 \mathrm{HB} 6 \mathrm{H}$ subunit contained one FAD. This result showed that the $3 \mathrm{HB} 6 \mathrm{H}$ from strain AD-3 is similar to Rj3HB6H (Montersino and van Berkel, 2012). $3 \mathrm{HB} 6 \mathrm{H}$ from strain $\mathrm{AD}-3$ also contained $\mathrm{PGs}$ like Rj3HB6H (Montersino et al., 2017), but we did not identify PEs. The PGs are the major lipid component of Escherichia coli cell membranes (Oursel et al., 2007). The phospholipids in $3 \mathrm{HB} 6 \mathrm{H}$ are used to increase their dimerization strength (Montersino et al., 2017). Similar to other hydroxylases, 3HB6H from strain $\mathrm{AD}-3$ utilizes $\mathrm{NADH}$ as the electron donor to complete the catalytic reaction (Steennis et al., 1973; Van Berkel and $\mathrm{Wj}, 1991)$. This protein converted 3-hydroxybenzoate to gentisate while consuming $\mathrm{NADH}$ in vivo and in vitro
(Figures 2B, 3C) and had no enzyme activity when salicylate and 4-hydroxybenzoate were used as substrates, similar to other 3hydroxybenzoate 6-hydroxylases (data not shown) (Gao et al., 2005; Yang et al., 2010; Montersino and van Berkel, 2012). The molecular weight of $3 \mathrm{HB} 6 \mathrm{H}$ from strain $\mathrm{AD}-3$ is similar to that of most 3HB6H enzymes, such as RHA1_ro01869 (Rhodococcus jostii RHA1), XlnD (Pseudomonas alcaligenes NCIMB 9867), and NagX (Polaromonas naphthalenivorans) (Gao et al., 2005; Park et al., 2007; Montersino and van Berkel, 2012).

\section{The Key Conditions of Enzyme Activity Metal lons and Temperature}

Comparing the effect of metal salts with XlnD, Ncgl 2923, and $\mathrm{MhbM}, \mathrm{Fe}^{3+}, \mathrm{Cu}^{2+}, \mathrm{Zn}^{2+}, \mathrm{Co}^{2+}$, and $\mathrm{Ba}^{2+}$ reduced the activity of all of the enzymes (Gao et al., 2005; Park et al., 2007; Yang et al., 2010). $\mathrm{Ca}^{2+}$ and $\mathrm{Mn}^{2+}$ also reduce the enzyme activity except for $3 \mathrm{HB} 6 \mathrm{H}$ from strain $\mathrm{AD}-3$. Additionally, $3 \mathrm{HB} 6 \mathrm{H}$ from $\mathrm{AD}-3$ showed high activity $(25.2 \mathrm{U} / \mathrm{mg})$ in phosphate buffer $(\mathrm{pH} 8.0)$ at $37^{\circ} \mathrm{C}$. This enzyme has relatively high activity after incubating at $16-37^{\circ} \mathrm{C}$ for $1 \mathrm{~h}$, but the activity is $7.21 \mathrm{U} / \mathrm{mg}$ when the system environment is at $16^{\circ} \mathrm{C}$. And there were high reaction speed at

TABLE 1 | The Kinetic Parameters of Wild Type and Mutant 3HB6H Enzymes.

\begin{tabular}{|c|c|c|c|c|c|c|c|c|c|}
\hline \multirow[t]{2}{*}{ Type } & \multirow[t]{2}{*}{ Activity (U/mg) } & \multirow{2}{*}{$\begin{array}{l}\text { Amount of } \\
\text { FAD binding } \\
\text { (mol/mol) }\end{array}$} & \multirow{2}{*}{$\begin{array}{l}\text { Hydroxylation } \\
\text { efficiency }(\%)\end{array}$} & \multicolumn{3}{|c|}{ ЗНB } & \multicolumn{3}{|c|}{ NADH } \\
\hline & & & & $K_{\mathrm{m}}(\mu \mathrm{M})$ & $k_{\text {cat }}\left(s^{-1}\right)$ & $k_{\text {cat }} / K_{\mathrm{m}}$ & $K_{\mathrm{m}}(\mu \mathrm{M})$ & $k_{\text {cat }}\left(s^{-1}\right)$ & $k_{\text {cat }} / K_{\mathrm{m}}$ \\
\hline WT & $15.4 \pm 2.2$ & $1.02 \pm 0.05$ & $88.0 \pm 7.6$ & $72.6 \pm 10.1$ & $5.7 \pm 0.2$ & 0.08 & $104.1 \pm 18.2$ & $7.8 \pm 0.4$ & 0.08 \\
\hline Q305P & $3.3 \pm 0.1$ & $0.14 \pm 0.02$ & $66.8 \pm 5.3$ & $91.3 \pm 13.5$ & $1.6 \pm 0.1$ & 0.02 & $95.9 \pm 23.2$ & $1.6 \pm 0.1$ & 0.02 \\
\hline Y306H & $3.4 \pm 0.1$ & $0.76 \pm 0.10$ & $82.4 \pm 1.7$ & $46.3 \pm 6.9$ & $1.5 \pm 0.1$ & 0.03 & $103.7 \pm 13.6$ & $1.6 \pm 0.3$ & 0.02 \\
\hline A308G & $4.8 \pm 0.3$ & $0.34 \pm 0.17$ & $79.3 \pm 1.0$ & $38.0 \pm 10.1$ & $2.3 \pm 0.1$ & 0.06 & $33.7 \pm 6.4$ & $2.0 \pm 0.1$ & 0.06 \\
\hline x & $1.2 \pm 0.1$ & $0.07 \pm 0.01$ & $68.1 \pm 3.9$ & $28.6 \pm 7.3$ & $0.5 \pm 0.1$ & 0.02 & $50.0 \pm 9.7$ & $0.6 \pm 0.1$ & 0.01 \\
\hline Y221F & $2.6 \pm 0.4$ & $1.05 \pm 0.1$ & $47.2 \pm 9.8$ & $164.2 \pm 14.0$ & $1.7 \pm 0.1$ & 0.01 & $86.7 \pm 10.8$ & $1.0 \pm 0.1$ & 0.01 \\
\hline
\end{tabular}


$42^{\circ} \mathrm{C}$ to $50^{\circ} \mathrm{C}$, but the enzyme lost activity rapidly. Therefore, $37^{\circ} \mathrm{C}$ is the optimal temperature which guarantee no loss of enzyme activity and ensure to keep high activity.

\section{Chloride Ion}

In the experiment to determine the effect of $\mathrm{pH}, 3 \mathrm{HB} 6 \mathrm{H}$ showed 2.3 times higher activity in phosphate buffer $(\mathrm{pH} 8.0)$ than in Tris- $\mathrm{HCl}(\mathrm{pH} 8.0)$. To explore whether $3 \mathrm{HB} 6 \mathrm{H}$ catalysed 3-hydroxybenzoate under high salinity conditions $(\mathrm{NaCl})$, we conducted a salinity experiment. Martelella strain AD-3, which is a moderate halophilic bacterium, can degrade 3-hydroxybenzoic acid in high salinity environments in which $\mathrm{NaCl}$ is the main source of salt. However, the activity of the purified $3 \mathrm{HB} 6 \mathrm{H}$ decreased significantly as the amount of salinity increased. This phenomenon is similar to that observed with other flavoproteins; $\mathrm{Cl}^{-}$has a strong inhibitory effect on flavoprotein monooxygenases (Steennis et al., 1973; Van Berkel and Wj, 1991; Montersino et al., 2013). In Rhodococcus jostii RHA1, the model of $3 \mathrm{HB} 6 \mathrm{H}$ monomer contains one chloride ion that was found to bind in front of the flavin ring and the $\mathrm{NH}$ backbone atoms. This binding site corresponds to the niche predicted to host the oxygen atoms of the flavin-hydroperoxide adduct formed upon reaction of the reduced flavin with oxygen. These findings indicate that negatively charged chlorine can interfere with the binding and/or reactivity of the enzymes with oxygen, $\mathrm{NADH}$, or both (Montersino et al., 2013).

\section{Binding to FAD and Substrate}

Based on the reported structure of $3 \mathrm{HB} 6 \mathrm{H}$ in Rhodococcus jostii RHA1 (Montersino et al., 2013) and the prediction of I-TASSER, Q305, Y306 and A308 are the binding sites for FAD. In this study, we found that the activity of the mutant enzymes decreased (Table 1). The FAD-binding ability of Y221F was similar to that of the wild-type enzyme. The $K_{\mathrm{m}}$ of $\mathrm{Y} 221 \mathrm{~F}$ for $3 \mathrm{HB}$ was the highest among wild-type and mutants, and showed 2.3 times that of the wild-type, however, its enzymatic activity was less than that of the wild-type. Therefore, it was concluded that Y221F may be associated with substrate binding. In Rj3HB6H, Tyr217 is the important residue for substrate binding, which results in a hydrogen-bond interaction with the carboxylate group of $3 \mathrm{HB}$. When substituting Tyr217, there is a substantial decrease or complete abolishment of substrate binding (Sucharitakul et al., 2015). Among them, $X$ was the three-point mutation type, with the lowest amount of enzymatic activity and FAD binding. This

\section{REFERENCES}

Cui, C. C., Li, Z. J., Qian, J. C., Shi, J., Huang, L., Tang, H. Z., et al. (2016). Complete genome of Martelella sp. AD-3, a moderately halophilic polycyclic aromatic hydrocarbons-degrading bacterium. J. Biotechnol. 225, 29-30. doi: 10.1016/j.jbiotec.2016.03.014

Cui, C. C., Ma, L., Shi, J., Lin, K. F., Luo, Q. S., and Liu, Y. D. (2014). Metabolic pathway for degradation of anthracene by halophilic Martelella sp. AD-3. Int. Biodeterior. Biodegradation 89, 67-73. doi: 10.1016/j.ibiod.2014. 01.012

Eggink, G., Engel, H., Vriend, G., Terpstra, P., and Witholt, B. (1990). Rubredoxin reductase of Pseudomonas oleovorans: structural relationship phenomenon illustrated that the three sites involved in FAD binding. Q305 might play the most important role among them because the activity and binding FAD of Q305P were lower than those of $\mathrm{A} 308 \mathrm{G}$ and $\mathrm{Y} 306 \mathrm{H}$. The $K_{\mathrm{m}}$ of Q305P to $3 \mathrm{HB}$ was greater than that of the wild-type, and the binding amount of FAD was smaller than that of the wild-type. Therefore, Q305 was related to the binding of the substrate and FAD. This result validates previous findings in $\mathrm{Rj} 3 \mathrm{HB} 6 \mathrm{H}$. When this site was changed to Glu, the enzyme lost activity. This site had a primary role in catalysis, possibly facilitating deprotonation of the substrate phenol (Montersino and van Berkel, 2012). When we changed Ala (308) to Gly, the activity and amount of FAD binding decreased. The reason may be the change of hydrophobic amino acid to hydrophilic amino acid and made it weaken the ability to combine with FAD. It coincided with the crystal structure of Rj3HB6H in which the A304 was related to bind FAD (Montersino and van Berkel, 2012).

\section{AUTHOR CONTRIBUTIONS}

HT and CC conceived and designed the experiments. XC performed the experiments. KL and YX analyzed the data. PX and YL contributed reagents, materials, and analysis tools.

\section{FUNDING}

This research was supported by the Research Projects of Environmental Protection Public Welfare Industry in China (201509035), the National Natural Science Foundation of China (41301329 and 51578240), the Chinese National Science Foundation for Excellent Young Scholars (31422004), Yangtze River Delta Technology Projects of Shanghai Municipal Science and Technology Commission (17295810602), and Excellent Team Program of Shanghai Academy of Agricultural Sciences [2017(A-03)].

\section{SUPPLEMENTARY MATERIAL}

The Supplementary Material for this article can be found online at: https://www.frontiersin.org/articles/10.3389/fmicb. 2018.01335/full\#supplementary-material

to other flavoprotein oxidoreductases based on one NAD and two FAD fingerprints. J. Mol. Biol. 212, 135-142. doi: 10.1016/0022-2836(90)90310-I

Eppink, M. H. M., van Berkel, W. J. H., and Schreuder, H. A. (1997). Identification of a novel conserved sequence motif in flavoprotein hydroxylases with a putative dual function in FAD/NAD(P)H binding. Protein Sci. 6, 2454-2458. doi: 10.1002/pro.5560061119

Feng, T. C., Cui, C. Z., Dong, F., Feng, Y. Y., Liu, Y. D., and Yang, X. M. (2012). Phenanthrene biodegradation by halophilic Martelella sp. AD-3. J. Appl. Microbiol. 113, 779-789. doi: 10.1111/j.1365-2672.2012.05386.x

Gao, X. L., Tan, C. L., Yeo, C. C., and Poh, C. L. (2005). Molecular and biochemical characterization of the $x \ln D$-encoded 3-hydroxybenzoate 6hydroxylase involved in the degradation of 2,5-xylenol via the gentisate 
pathway in Pseudomonas alcaligenes NCIMB 9867. J. Bacteriol. 187, 7696-7702. doi: 10.1128/JB.187.22.7696-7702.2005

Hopper, D. J., and Chapman, P. J. (1971). Gentisic acid and its 3- and 4methyl-substituted homologoues as intermediates in the bacterial degradation of $m$-cresol, 3,5-xylenol and 2,5-xylenol. Biochem. J. 122, 19-28. doi: 10.1042/ bj1220019

Hopper, D. J., Chapman, P. J., and Dagley, S. (1971). The enzymic degradation of alkyl-substituted gentisates, maleates and malates. Biochem. J. 122, 29-40. doi: $10.1042 / b j 1220029$

Huang, L., Hu, H. Y., Tang, H. Z., Liu, Y. D., Xu, P., Shi, J., et al. (2015). Identification and characterization of a novel gentisate 1,2-dioxygenase dene from a halophilic Martelella strain. Sci. Rep. 5:14307. doi: 10.1038/srep 14307

Huijbers, M. M. E., Montersino, S., Westphal, A. H., Tischler, D., and van Berkel, W. J. H. (2014). Flavin dependent monooxygenases. Arch. Biochem. Biophys. 544, 2-17. doi: 10.1016/j.abb.2013.12.005

Ko, J. J., Shimizu, Y., Ikeda, K., Kim, S. K., Park, C. H., and Matsui, S. (2009). Biodegradation of high molecular weight lignin under sulfate reducing conditions: lignin degradability and degradation by-products. Bioresour. Technol. 100, 1622-1627. doi: 10.1016/j.biortech.2008.09.029

Kruger, N. J. (1994). The Bradford method for protein quantitation. Methods Mol. Biol. 32, 9-15. doi: 10.1385/0-89603-268-X:9

Liu, D. Q., Liu, H., Gao, X. L., Leak, D. J., and Zhou, N. Y. (2005). Arg169 is essential for catalytic activity of 3-hydroxybenzoate 6-hydroxylase from Klebsiella pneumoniae M5a1. Microbiol. Res. 160, 53-59. doi: 10.1016/j.micres. 2004.09.003

Montersino, S., Orru, R., Barendregt, A., Westphal, A. H., Van Duijn, E., Mattevi, A., et al. (2013). Crystal structure of 3-hydroxybenzoate 6-hydroxylase uncovers lipid-assisted flavoprotein strategy for regioselective aromatic hydroxylation. J. Biol. Chem. 288, 26235-26245. doi: 10.1074/jbc.M113. 479303

Montersino, S., Poele, E. T., Orru, R., Westphal, A. H., Barendregt, A., Heck, A. J. R., et al. (2017). 3-Hydroxybenzoate 6-hydroxylase from Rhodococcus jostii RHA1 contains a phosphatidylinositol cofactor. Front. Microbiol. 8:1110. doi: $10.3389 /$ fmicb.2017.01110

Montersino, S., Tischler, D., Gassner, G. T., and van Berkel, W. J. H. (2011). Catalytic and structural features of flavoprotein hydroxylases and epoxidases. Adv. Synth. Catal. 353, 2301-2319. doi: 10.1002/adsc.201100384

Montersino, S., and van Berkel, W. J. H. (2012). Functional annotation and characterization of 3-hydroxybenzoate 6-hydroxylase from Rhodococcus jostii RHA1. Biochim. Biophys. Acta 1824, 433-442. doi: 10.1016/j.bbapap.2011. 12.003

Narváez, L., Cano, E., and Bastidas, D. M. (2005). 3-Hydroxybenzoic acid as AISI 316L stainless steel corrosion inhibitor in a $\mathrm{H} 2 \mathrm{SO} 4-\mathrm{HF}-\mathrm{H} 2 \mathrm{O} 2$ pickling solution. J. Appl. Electrochem. 35, 499-506. doi: 10.1007/s10800-0050291-1

Oursel, D., Loutelierbourhis, C., Orange, N., Chevalier, S., Norris, V., and Lange, C. M. (2007). Lipid composition of membranes of Escherichia coli by liquid chromatography/tandem mass spectrometry using negative electrospray ionization. Rapid Commun. Mass Spectrom. 21, 1721-1728. doi: 10.1002/rcm. 3013

Panke, S., Witholt, B., Schmid, A., and Wubbolts, M. G. (1998). Towards a biocatalyst for (S)-styrene oxide production: characterization of the styrene degradation pathway of Pseudomonas sp. VLB120. Appl. Environ. Microbiol. 64, 2032-2043.
Park, M., Jeon, Y., Jang, H. H., Ro, H. S., Park, W., Madsen, E. L., et al. (2007). Molecular and biochemical characterization of 3-hydroxybenzoate 6-hydroxylase from Polaromonas naphthalenivorans CJ2. Appl. Environ. Microbiol. 73, 5146-5152. doi: 10.1128/AEM.00782-07

Roy, A., Kucukural, A., and Zhang, Y. (2010). I-TASSER: a unified platform for automated protein structure and function prediction. Nat. Protoc. 5, 725-738. doi: $10.1038 /$ nprot.2010.5

Steennis, P. J., Cordes, M. M., Hilkens, J. G. H., and Müller, F. (1973). On the interaction of para-hydroxybenzoate hydroxylase from Pseudomonas fluorescens with halogen ions. FEBS Lett. 36, 177-180. doi: 10.1016/00145793(73)80363-1

Sucharitakul, J., Medhanavyn, D., Pakotiprapha, D., van Berkel, W. J. H., and Chaiyen, P. (2015). Tyr217 and His213 are important for substrate binding and hydroxylation of 3-hydroxybenzoate 6-hydroxylase from Rhodococcus jostii RHA1. FEBS J. 283, 860-881. doi: 10.1111/febs.13636

Sucharitakul, J., Tongsook, C., Pakotiprapha, D., van Berkel, W. J. H., and Chaiyen, P. (2013). The reaction kinetics of 3-hydroxybenzoate 6-hydroxylase from Rhodococcus jostii RHAl provide an understanding of the parahydroxylation enzyme catalytic cycle. J. Biol. Chem. 288, 35210-35221. doi: 10.1074/jbc.M113.515205

Tang, H. Z., Yao, Y. X., Zhang, D. K., Meng, X. Z., Wang, L. J., Yu, H., et al. (2011). A novel NADH-dependent and FAD-containing hydroxylase is crucial for nicotine degradation by Pseudomonas putida. J. Biol. Chem. 286, 39179-39187. doi: 10.1074/jbc.M111.283929

Van Berkel, W. J. H., and Wj, V. D. T. (1991). Purification and characterisation of 3hydroxyphenylacetate 6-hydroxylase: a novel FAD-dependent monooxygenase from a Flavobacterium species. Eur. J. Biochem. 201, 585-592. doi: 10.1111/j. 1432-1033.1991.tb16318.x

Wang, L. H., Hamzah, R. Y., Yu, Y., and Tu, S. C. (1987). Pseudomonas cepacia $3-$ hydroxybenzoate 6-hydroxylase: induction, purification, and characterization. Biochemostry 26, 1099-1104. doi: 10.1021/bi00378a017

Wierenga, R. K., Terpstra, P., and Hol, W. G. (1986). Prediction of the occurrence of the adp-binding beta alpha beta-fold in proteins, using an amino acid sequence fingerprint. J. Mol. Biol. 187, 101-107. doi: 10.1016/0022-2836(86) 90409-2

Yang, Y. F., Zhang, J. J., Wang, S. H., and Zhou, N. Y. (2010). Purification and characterization of the ncgl2923-encoded 3-hydroxybenzoate 6hydroxylase from Corynebacterium glutamicum. J. Basic Microbiol. 50, 599-604. doi: $10.1002 /$ jobm.201000053

Yano, K., and Arima, K. (1958). Metabolism of aromatic compounds by bacteria: II. $m$-Hydroxybenzoic acid hydroxylase A and B; 5-Dehydroshikimic acid, a precursor of protocatechuic acid, a new pathway from salicylic acid to gentisic acid. J. Gen. Appl. Microbiol. 4, 241-258. doi: 10.2323/jgam.4.241

Conflict of Interest Statement: The authors declare that the research was conducted in the absence of any commercial or financial relationships that could be construed as a potential conflict of interest.

Copyright $\odot 2018$ Chen, Tang, Liu, Xu, Xue, Lin and Cui. This is an open-access article distributed under the terms of the Creative Commons Attribution License (CC BY). The use, distribution or reproduction in other forums is permitted, provided the original author(s) and the copyright owner(s) are credited and that the original publication in this journal is cited, in accordance with accepted academic practice. No use, distribution or reproduction is permitted which does not comply with these terms. 